\title{
Improvement of Microstructure and Mechanical Behavior of Gas Tungsten Arc Weldments of Alloy C-276 by Current Pulsing
}

\author{
M. Manikandan - N. Arivazhagan - M. Nageswara Rao - G. Madhusudhan Reddy
}

Received: 18 March 2014/Revised: 17 June 2014/Published online: 12 December 2014

(C) The Chinese Society for Metals and Springer-Verlag Berlin Heidelberg 2014

\begin{abstract}
Superalloy C-276 is known to be prone to hot cracking during fusion welding by Gas Tungsten Arc method. Microsegregation occurring during cooling of fusion zone with consequent appearance of topologically close-packed phases $\mathrm{P}$ and $\mu$ has been held responsible for the observed hot cracking. The present work investigated the possibility of suppressing the microsegregation in weldments by resorting to current pulse. Weldments were made by continuous current gas tungsten arc welding and pulsed current gas tungsten arc welding using ERNiCrMo-4 filler wire. The weld joints were studied with respect to microstructure, microsegregation, and mechanical properties. Optical microscopy and scanning electron microscopy were employed to study the microstructure. Energy-Dispersive X-ray Spectroscopy was carried out to evaluate the extent of microsegregation. Tensile testing was carried out to determine the strength and ductility. The results show that the joints fabricated with pulsed current gave rise to narrower welds with practically no heat affected zone, a refined microstructure in the fusion zone, reduced microsegregation, and superior combination of mechanical properties.
\end{abstract}

KEY WORDS: Alloy C-276; Pulsed current gas tungsten arc welding; Microsegregation

\section{Introduction}

Hastelloy C-276 is a nickel-based single phase superalloy. The main alloying elements are $\mathrm{Cr}, \mathrm{Mo}, \mathrm{Fe}$, and $\mathrm{W}$. The alloy is designed based on solid solution strengthening; there is no precipitation hardening operating in this alloy [1]. Chromium facilitates the formation of passive films in a wide range of oxygen bearing environments, thereby contributing to alloy's corrosion resistance. Chromium also contributes to solid solution strengthening. Molybdenum

Available online at http://link.springer.com/journal/40195

M. Manikandan $(\varangle) \cdot$ N. Arivazhagan $\cdot$ M. Nageswara Rao School of Mechanical and Building Sciences, VIT University, Vellore 632 014, India

e-mail: manikandan.m@vit.ac.in

G. Madhusudhan Reddy

Defence Metallurgical and Research Laboratory, Hyderabad, India imparts the alloy resistance to both oxidizing and reducing chemicals. In addition, by virtue of its large atomic size compared to that of nickel, it has a strong solid solution strengthening effect [2]. The behavior of $\mathrm{W}$ is similar to that of Mo. It is in fact an even more effective solid solution strengthener than Mo. Compared to other common engineering materials such as SS 316, Monel 400, Inconel 625, alloy C-276 exhibits better corrosion resistance to marine environments involving particularly crevice corrosion conditions [3]. Due to its excellent resistance to a wide spectrum of corrosive environments and superior mechanical properties, the alloy finds application in a variety of industries-nuclear sector, chemical processing, aerospace, marine engineering etc. $[4,5]$.

Welding is a very important process which is used for the manufacturing of various products. Arc welding is a commonly used technique. The most common arc welding methods are Gas Tungsten Arc Welding (GTAW) and Gas Metal Arc Welding (GMAW). The choice of filler wire is an important part of the weld design process. Two types of 
filler wire have been employed: (i) filler wire with composition matching with that of base metal; (ii) overalloyed filler wire where alloying elements are present in the filler wire material at a level higher than that in base metal. For most of the applications, filler wire with base metal composition is adequate [6]. For situations where the weld joints are expected to serve in highly aggressive environments, overalloyed filler wire is selected [2]. For the present study, filler wire with essentially matching composition (ERNiCrMo-4) has been chosen.

The welding of alloy C-276 is beset with some problems and these were documented in the literature by different workers. It was emphasized that deleterious phases appear when the material is exposed to high temperatures. Tawancy [7] reported the precipitation of $M_{2} \mathrm{C}$ and $\mu$ phases in the form of a continuous layer at the grain boundary when the alloy is aged at $537{ }^{\circ} \mathrm{C}$ for a long time, leading to a reduced tensile elongation and higher corrosion rate in boiling sulfuric-ferric sulfate solution. Akhtar et al. [5] reported the precipitation of molybdenum-rich $\mu$ phase after aging at $850{ }^{\circ} \mathrm{C}$ that lead to a drop in impact energy; a completely intercrystalline brittle fracture occurred after aging for $120 \mathrm{~h}$. Raghavan et al. [8] observed the formation of three distinct phases when the alloy is aged in the temperature range of $650-900{ }^{\circ} \mathrm{C}$, where the most abundant was the molybdenum-rich $\mu$ phase, the second most abundant was molybdenum-rich $M_{6} \mathrm{C}$ carbide, and the third phase was tentatively identified as $\mathrm{P}$ phase with a composition remarkably similar to that of $\mu$ phase. Both $\mu$ and $\mathrm{P}$ phases belong to the group of topologically close-packed (TCP) phases. In general, the TCP phases in superalloys have a detrimental effect on several properties. They rupture strength, tensile ductility, and impact toughness at room temperature and corrosion resistance suffer a reduction when TCP phases appear in the microstructure [9].

The welding metallurgy of alloy C-276 gets complicated by the appearance of these TCP phases in fusion zone during welding. Cieslak et al. [10] carried out arc welding studies on alloys C-4, C-22, and C-276. All these are highly corrosion resistant $\mathrm{Ni}$-based alloys derived from $\mathrm{Ni}-\mathrm{Cr}-\mathrm{Mo}$ ternary system. Cieslak et al. [10] found that elemental segregation occurs during welding, leading to the formation of brittle TCP phases $\mathrm{P}$ and $\mu$ in alloys $\mathrm{C}-22$ and $\mathrm{C}-276$. It is also reported that alloy $\mathrm{C}-276$ shows the highest susceptibility to hot cracking among the three alloys. They established that weld metal hot cracks are associated with intermetallic secondary solidification constituents $\mathrm{P}$ and $\mu$. Perricone and Dupont [11] reviewed the subject of TCP phases in superalloys based on Ni-Cr-Mo system and summarized that the occurrence of TCP phases $\mu$ and P in alloy C-276 adversely affects the weldability and other properties of interest.

The TCP phases $\mathrm{P}$ and $\mu$ are both rich in Mo and $\mathrm{W}$, i.e., these elements preferentially partition into $\mathrm{P}$ and $\mu$ phases, depleting the gamma matrix of these elements to some extent. The higher the level at which Mo and $\mathrm{W}$ are present in the Ni-Cr-Mo-based alloy, the higher is the propensity to the formation of these brittle phases. For example, Perricone and DuPont [11] found no evidence of the occurrence of these phases in the weldments of a $12 \% \mathrm{Mo}$ containing $\mathrm{Ni}-\mathrm{Cr}-\mathrm{Mo}$ alloy. But upon increasing the $\mathrm{Mo}$ level to $24 \%$ at the expense of $\mathrm{Ni}, \mathrm{P}$, and $\mu$ phases appear in the weld microstructure. Zheng et al. [12] also reported that high concentration of $\mathrm{Mo}$ and $\mathrm{W}$ in $\mathrm{Ni}-\mathrm{Cr}-\mathrm{Mo}$ alloys leads to the occurrence of TCP phases during solidification. These phases find place in the ternary equilibrium diagram for the Ni-Cr-Mo system. P phase forms at relatively high temperatures compared to $\mu$ phase. The later phase is believed to be the product of solid-state transformation from the former.

The core issue is how to bring down the susceptibility of alloy C-276 to hot cracking during welding. Based on the foregoing, this can be achieved by preventing the formation of deleterious secondary constituents $\mathrm{P}$ and $\mu$ during fusion welding. This in turn can be realized if one can cut down on the severity of microsegregation occurring during fusion welding.

In this context, the pulsed current gas tungsten arc welding (PCGTAW) has shown some promise. It is a variation of constant current gas tungsten arc welding (CCGTAW), henceforth referred to simply as GTAW. Pulsing involves cycling of the welding current from a high level to a low level at a selected frequency. In contrast to GTAW, during PCGTAW, the heat energy required to melt the base material is supplied only during peak current pulses (for brief intervals of time). The instantaneous cooing rates are higher in PCGTAW with a shorter solidification time.

It is well documented that higher cooling rates and shorter solidification times will lead to reduced elemental segregation, improved microstructure, freedom from unwanted presence of deleterious secondary constituents, and improved mechanical properties of weld joints. For example, Radhakrishna et al. [13] compared the weld joints produced by GTAW and Electron Bean Welding (EBW) in superalloy 718 and concluded that rapid solidification taking place in EBW leads to reduced elemental segregation in weld joints. Farahani et al. [14] studied the weld joints produced in superalloy 617; they concluded that PCGTAW resulted in finer grain size in fusion zone and superior mechanical properties of weld joints compared to continuous current GTAW. Ma et al. [15] reported that microsegregation in $\mathrm{C}-276$ joints produced by pulsed laser beam welding is relatively less compared to the situation obtained with arc welding process. Janakiram et al. [16] studied the effect of pulsing on weldments produced in superalloy 718; their finding was that pulsing brought down the severity of microsegregation with consequent reduction in the amount of Laves phase formed in the fusion zone 
during cooling. Janakiram [17] reported the refinement of microstructure in fusion zone and improved mechanical properties of weld joints after current pulsin. Manikandan et al. [18] compared the quality of weldments produced by GTAW and PCGTAW in superalloy 718 and concluded that pulsed current mode achieved maximum instantaneous cooling rate with consequent reduction in the amount of deleterious Laves phase in the fusion zone.

There is no published literature on the relative quality of weldments produced in superalloy C-276 by GTAW and PCGTAW, with particular reference to the extent of microsegregation in fusion zone, microstructure in fusion zone and HAZ, the occurrence of deleterious secondary constituents during cooling and mechanical behavior of weld joints. The aim of the present research is to bridge this knowledge gap. The expectation has been that a reduction in severity of microsegregation by switching over to PCGTAW would help in keeping the deleterious TCP phases at bay, and thereby improving the resistance that the alloy offers to hot cracking during welding.

\section{Experimental}

Alloy C-276 was procured in the form of hot rolled plate and was in solution annealed condition. Thoriated tungsten electrodes, $2.4 \mathrm{~mm}$ in diameter, were used to carry out the welding process. Argon was used as the shielding gas; the flow rate was $15 \mathrm{~L} / \mathrm{min}$. The chemical compositions of parent metal and filler wire are listed in Table 1. The process parameters employed for joining the alloy were chosen based on data in the literature. The suitability of the parameters so chosen was then confirmed by the bead on plate welding; the parameters are shown in Table 2. The standard square butt welding was carried out by continuous and pulsed mode of GTA welding process using ERNiCrMo-4 filler metal. Figure 1 shows the welded samples. $\mathrm{X}$-ray radiography and macroexamination were carried out to qualify the weld joints and to find the depth of penetration and fusion zone size. Samples which include different zones of fusion zone, heat affect zone (HAZ), and base metal were then cut in a plane transverse to the weld bead, and used for microstructure imaging using optical microscope and scanning electron microscope (SEM). Standard procedures were followed to prepare the samples for microscopic examination. The etchant used to reveal the microstructure was made of $80 \mathrm{~mL} \mathrm{HCl}, 4 \mathrm{~mL} \mathrm{HNO}_{3}$, $1 \mathrm{~g} \mathrm{CuCl}_{2}$, and $20 \mathrm{~mL}$ glycerol. Energy-Dispersive X-ray Spectroscopy (EDS) analysis was carried out on the weldment to evaluate the microsegregation with reference to matrix metal $\mathrm{Ni}$ and alloying elements $\mathrm{Cr}, \mathrm{Mo}, \mathrm{W}$, and Fe. Transverse tensile coupons as per ASTM E8/8 M standard were prepared by wire cut EDM process. Tensile testing was performed at room temperature at a strain rate of $2 \mathrm{~mm} / \mathrm{min}$. Three trials on each type weldment were conducted to check the reproducibility of the results.

\section{Results and Discussion}

\subsection{Macrostructure of GTA and PCGTA Weld Joints}

Macroexamination was carried out on welds produced by GTA and PCGTA methods, and the macrophotographs are shown in Fig. 2a, b respectively. The fusion zone as well as HAZ showed complete freedom from cracking. There was no problem of lack of penetration. Improper selection of weld consumables and non-optimal choice of heat input during welding can cause problems of cracking in fusion zone/HAZ in Ni-Cr-Mo alloys [19]. No such cracking was noticed in the present study, indicating that the parameters adopted to carry out the GTAW and PCGTAW were adequate to produce defect-free welds in alloy C-276. It is further observed that PCGTA welds have narrower fusion zone width than GTA welds. This is due to lower heat input and consequently smaller fusion zone of the pulsed current mode.

Table 1 Chemical composition of base metal and filer wire (wt\%)

\begin{tabular}{llllllllllllll}
\hline Material & Mo & Cr & W & Co & Mn & Fe & Si & V & Cu & P & S & C & Ni \\
\hline Hastelloy C-276 & 16.36 & 15.83 & 3.45 & 0.05 & 0.41 & 6.06 & 0.02 & 0.17 & - & 0.005 & 0.002 & 0.005 & Bal \\
ERNiCrMo-4 & 17.00 & 16.5 & 4.5 & 2.50 & 1.0 & 7.0 & 0.08 & - & 0.5 & 0.04 & 0.03 & 0.02 & Bal \\
\hline
\end{tabular}

Table 2 Process parameters for welding of alloy C-276 using GTA and PCGTA methods, employing ERNiCrMo-4 filler

\begin{tabular}{llllllll}
\hline $\begin{array}{l}\text { Welding } \\
\text { method }\end{array}$ & $\begin{array}{l}\text { Current } \\
(\mathrm{A})\end{array}$ & $\begin{array}{l}\text { Voltage } \\
(\mathrm{V})\end{array}$ & $\begin{array}{l}\text { Peak current } \\
(\mathrm{A})\end{array}$ & $\begin{array}{l}\text { Background } \\
\text { current }(\mathrm{A})\end{array}$ & $\begin{array}{l}\text { Pulse frequency } \\
(\mathrm{Hz})\end{array}$ & $\begin{array}{l}\text { Pulse on } \\
\text { time }\end{array}$ & $\begin{array}{l}\text { Welding speed } \\
(\mathrm{mm} / \mathrm{s})\end{array}$ \\
\hline GTA & 150 & 13.2 & & & & $\begin{array}{l}\text { Heat input } \\
(\mathrm{J} / \mathrm{mm})\end{array}$ \\
PCGTA & & & 200 & 100 & 6 & $50 \%$ & 1.54 \\
\hline
\end{tabular}



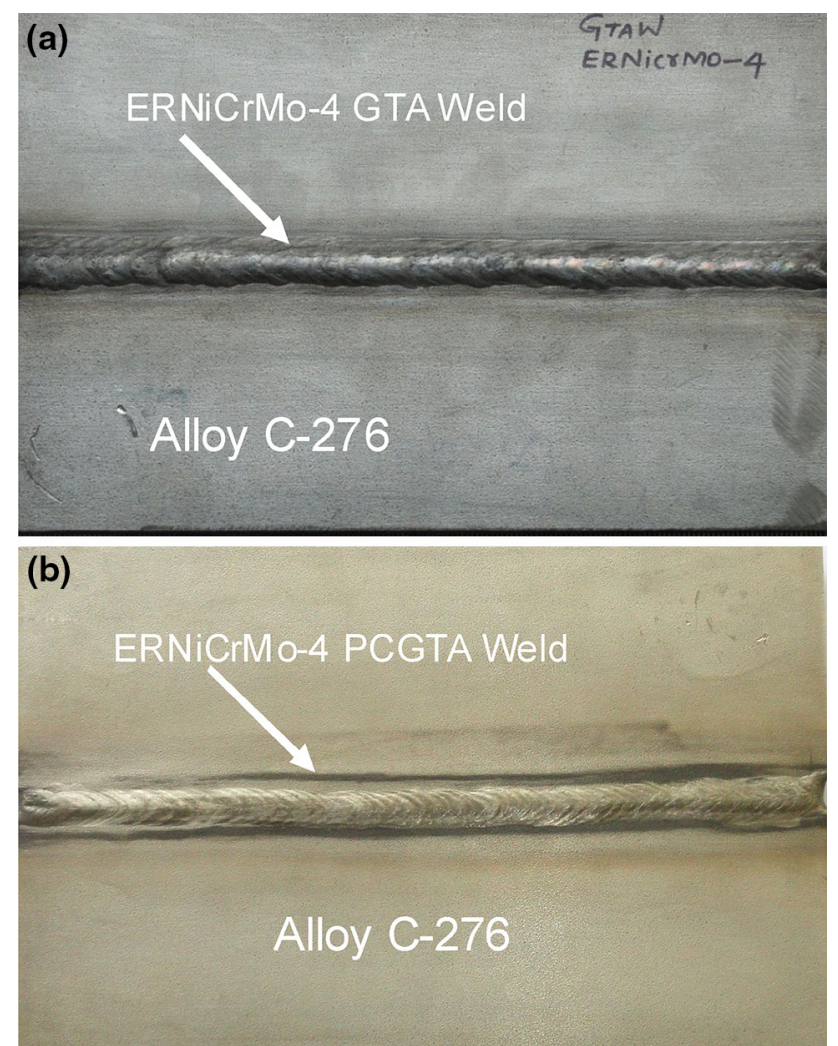

Fig. 1 Photographs of weld joints: a ERNiCrMo-4 GTAW; b ERNiCrMo-4 PCGTAW

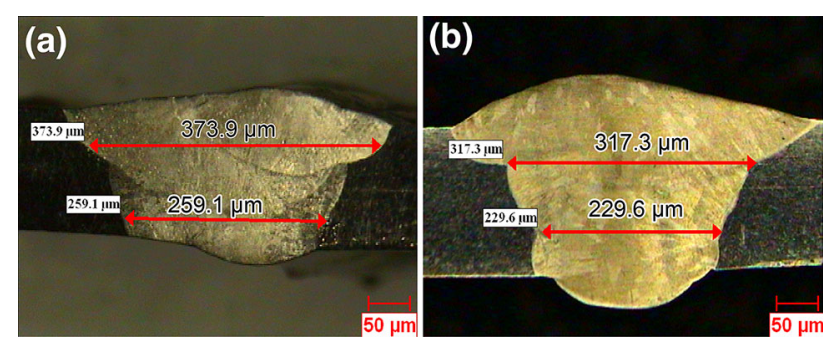

Fig. 2 Macrostructure of weld joints: a ERNiCrMo-4 GTA weld; b ERNiCrMo-4 PCGTA weld

\subsection{Optical Microscopic Examination of the GTA and PCGTA Weldments}

Figure 3 shows the optical micrograph of the base metal for reference. The microstructure consists of equiaxed grains with well-defined grain boundaries. Annealing twins are observed in several grains. Figure 4 shows the optical micrographs of different regions of the weld joint produced by GTAW. Figure 4a shows the microstructure of a region close to the center of the fusion zone. There are areas showing columnar dendrites; in some areas cellular structure is observed. A solidification grain boundary runs nearly diagonally through the micrograph. Figure $4 \mathrm{~b}$ shows the

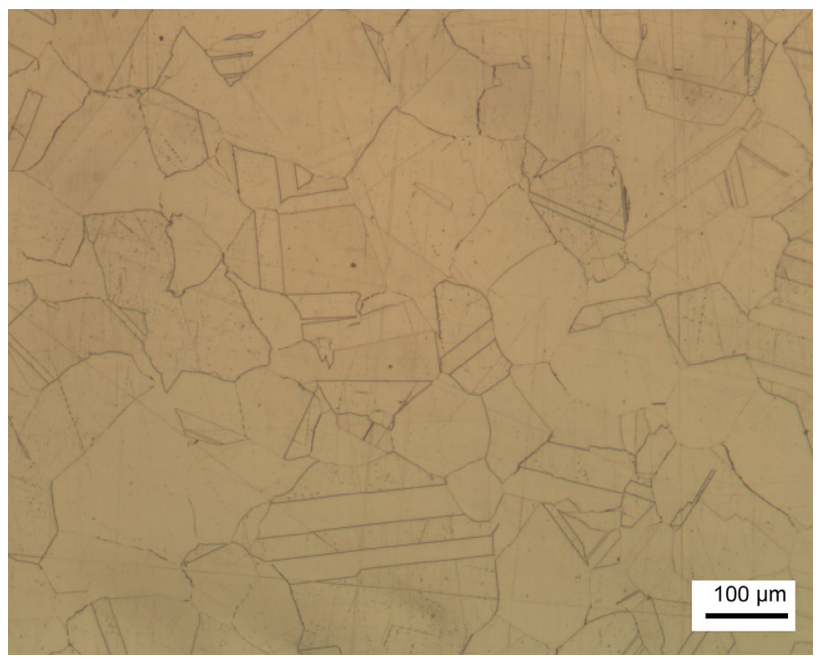

Fig. 3 Microstructure of alloy C-276 in the as-received condition

microstructure of fusion zone boundary region. A heat affect zone where grain coarsening can be clearly delineated to the right of the fusion zone can be seen in the figure. There is no evidence of partially melted zone in HAZ. Figure $4 \mathrm{c}$ shows the microstructure of a region containing both fusion zone/ HAZ transition and weld pass interface.

Figures 5 shows the optical microstructures of equivalent regions of weld joint produced by PCGTAW. Figure 5a is the microstructures of a region close to the center of the fusion zone. A cellular structure dominates the appearance; no columnar dendrites like the ones seen in GTA case were present. Even here a solidification grain boundary can be seen running through (shown by arrow). Figure 5 b shows the microstructure of fusion zone immediately next to the base metal. No grain coarsening is noticed next to the fusion zone, neither the existence of HAZ next to the fusion zone. Figure $5 \mathrm{c}$ shows the microstructure of a region containing both fusion zone/base metal transition and weld pass interface.

\subsection{Scanning Electron Microscopic Examination of GTA and PCGTA Weld Joints}

Figure 6 shows the SEM images and EDS results of GTA weldments. Figure $6 \mathrm{a}$ is the micrograph of a region close to the center of the fusion zone. Both columnar dendrites and cellular structure were observed in the microstructure. Figure $6 \mathrm{~d}$ is a micrograph of a region containing fusion zone/HAZ transition. Figure 7 shows the SEM images and EDS results of corresponding regions in PCGTA weldments. Figure $7 \mathrm{a}$ is a micrograph of a region close to the center of the fusion zone. A cellular structure dominates the appearance. Figure $7 \mathrm{~d}$ is a micrograph of a region containing the fusion zone/base metal transition. The fusion zone immediately to the left of the transition line shows a columnar structure. The occurrence of cellular 

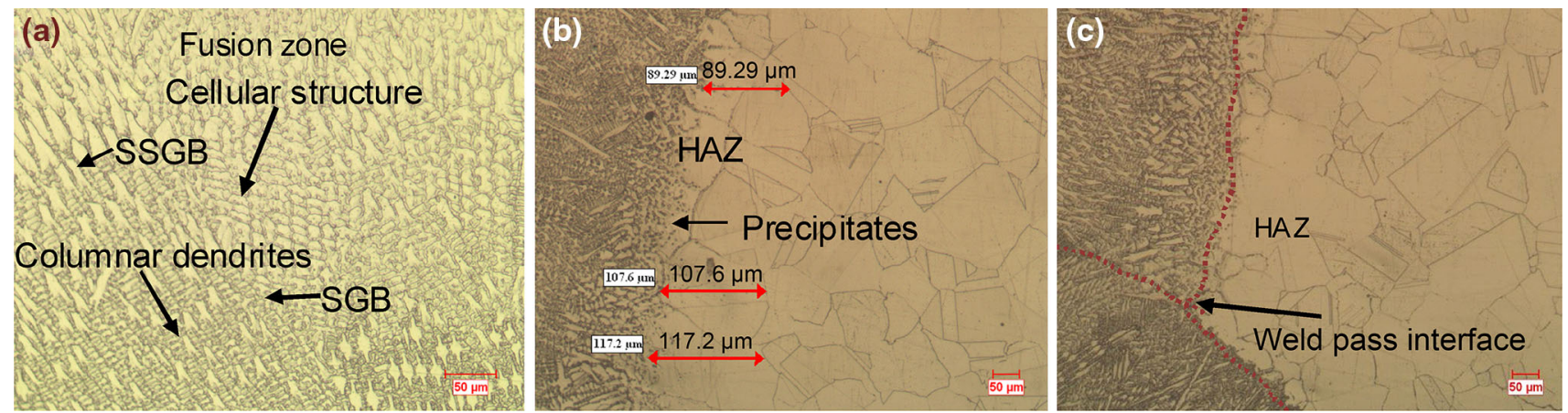

Fig. 4 Micrographs of weld joints produced by ERNiCrMo-4 GTAW: a Fusion Zone; b Weld Interface; c Weld Pass Interface
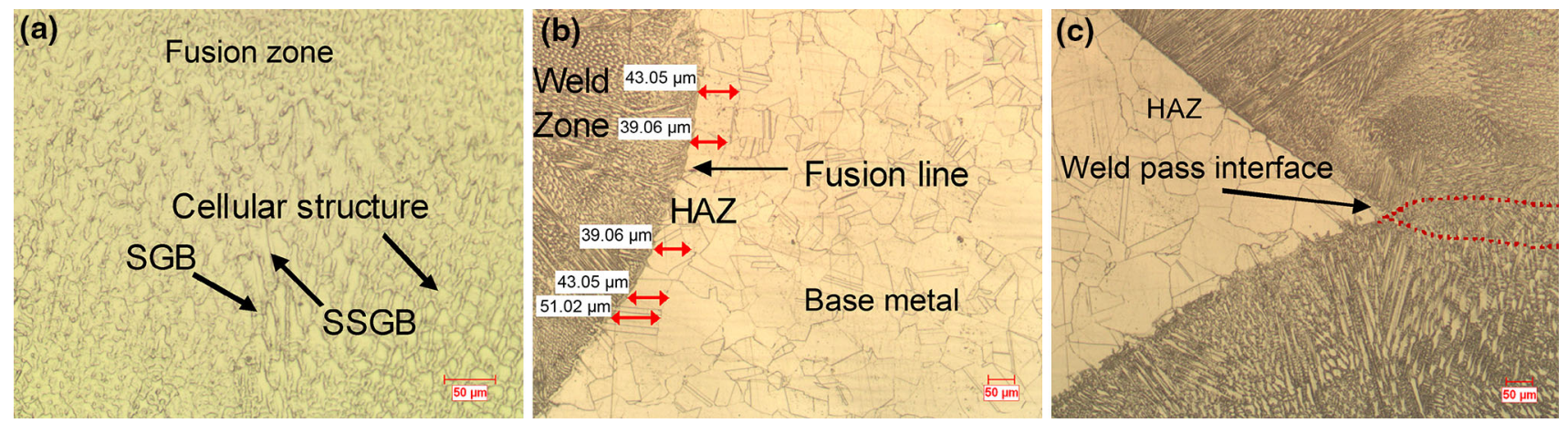

Fig. 5 Micrographs of weld joints produced by ERNiCrMo-4 PCGTAW: a Fusion Zone; b Weld Interface; c Weld Pass Interface

structure in the weld interior and columnar dendrites close to the fusion boundary can be explained on the basis of prevailing thermal gradient. Thermal gradients in a weld pool are steeper at regions close to fusion boundary than in weld interior [20]. The steep thermal gradients prevailing the fusion boundary favor columnar dendritic growth in a direction opposite to that of heat extraction [16]. Toward the weld center, however, the thermal gradients are not so steep, which, in combination with the very rapid cooling rates prevailing in the PCGTAW, lead to the formation of fine cell structure/equiaxed dendrites.

Both optical microscopic examination and scanning electron microscopic examination reveal that there is a microstructure refinement when one switches over from GTAW to PCGTAW. Optical microscopy showed that columnar dendrites present in fusion zone in GTAW do not appear any more in PCGTAW; a relatively fine cell structure dominates with PCGTAW. Similarly, the SEM photographs show that the columnar dendrites present in fusion zone in GTAW give way to a $100 \%$ relatively fine cell structure on switching over to PCGTAW. PCGTAW causes breakage of dendrite arms contributing to the refinement. As brought out in the Introduction Section, a refinement of microstructure of weld fusion zone in superalloys 718 [16] and 617 [14] was reported on switching over from GTAW to PCGTAW. Microscopic examination also brings out another difference; whereas there is a welldefined HAZ next to fusion zone in case of GTAW, HAZ is literally non-existent in the microstructure obtained with PCGTAW. This is to be attributed to the lower heat input associated with the pulsed current mode.

\subsection{EDS Analysis of GTA and PCGTA Weldments}

Microsegregation of alloying elements in fusion zone was evaluated by conducting EDS analysis using the EDAX facility available with the scanning electron microscope. Evaluation was carried out on the center part of the fusion zone as well as on the fusion zone area immediately adjoining HAZ/base metal. Both GTA and PCGTA weldments were examined. The main alloying elements in grade $\mathrm{C}-276$ are $\mathrm{Ni}, \mathrm{Cr}, \mathrm{Mo}, \mathrm{W}$, and Fe. All of them, with the exception of $\mathrm{Cr}$, show a tendency of microsegregation. These elements are also present in $\mathrm{P}$ and $\mu$ phases which may occur in the fusion zone during cooling. It was, hence, considered necessary to monitor the microsegregation with respect to all these five elements.

The EDS results for the GTA weldments are shown in Fig. 6. Figure $6 b, c$ are the results from the center part of the fusion zone. Figure $6 \mathrm{~b}$ addresses the subgrain boundary, while Fig. $6 c$ covers the subgrain body. It is noted that the subgrain boundary is enriched in Mo and impoverished in Ni and W compared to subgrain body. Microsegregation 

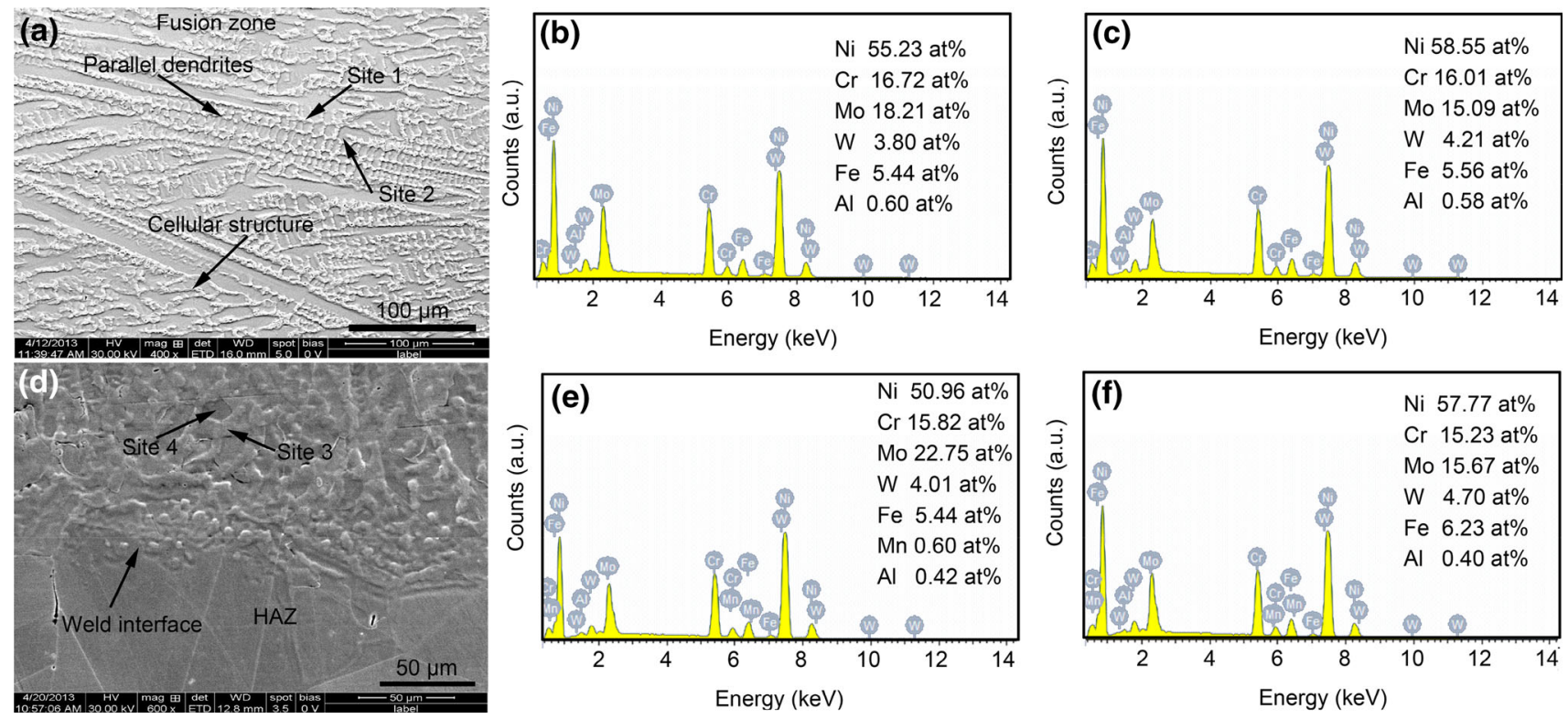

Fig. 6 SEM/EDAX analysis of GTA welded alloy C-276 with ERNiCrMo-4 filler wire for different regions of the weldments: a SEM image of weld zone; b EDAX result of weld subgrain boundary (Site 1); c EDAX result of weld subgrain body (Site 2); d SEM image of HAZ and Interface; e EDAX result of weld interface-subgrain boundary (Site 3); f EDAX result of weld interface-subgrain body (Site 4)
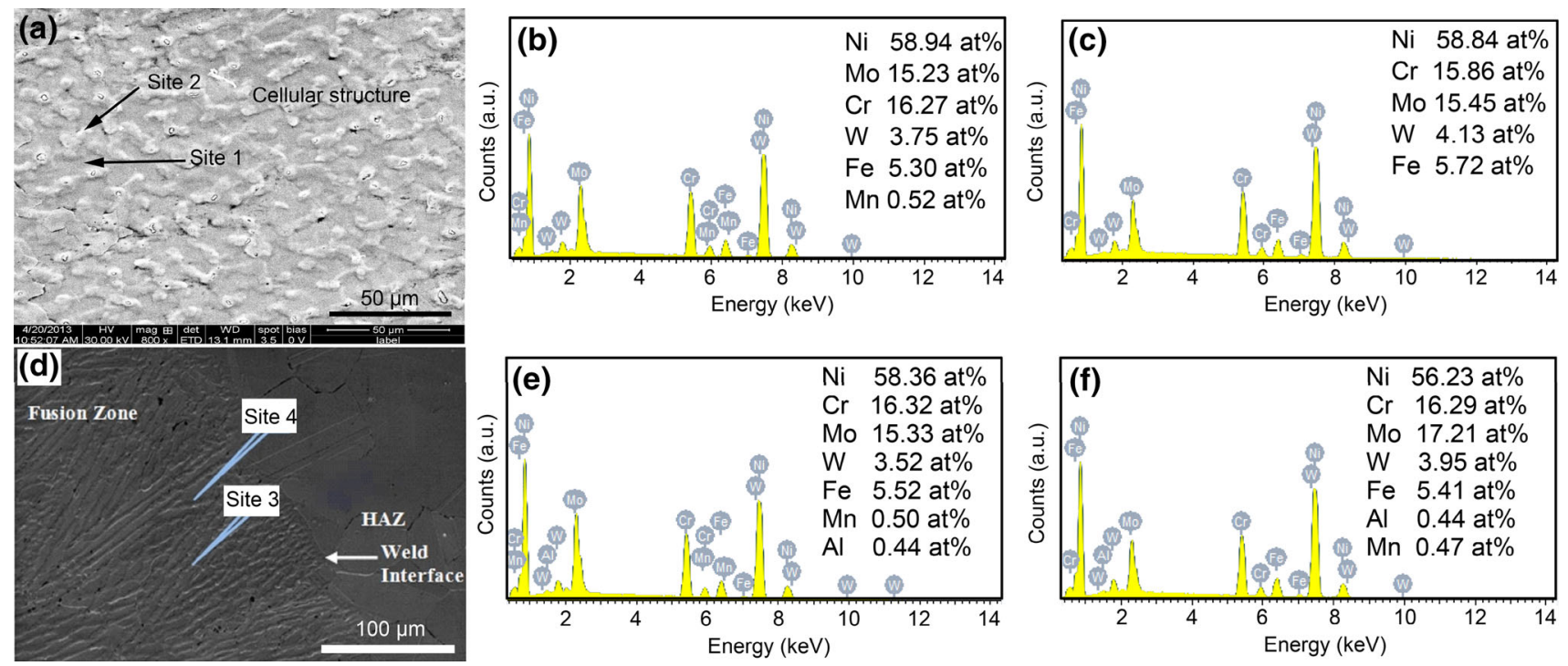

Fig. 7 SEM/EDAX analysis of PCGTA welded C-276 alloy with ERNiCrMo-4 filler wire for different regions of the weldment: a SEM image of weld zone; b EDAX result of weld subgrain boundary (Site 1); c EDAX result of weld subgrain body (Site 2); d SEM image of HAZ and Interface; e EDAX result of weld interface-subgrain boundary (Site 3); f EDAX result of weld interface-subgrain body (Site 4)

was not noticed to any significant extent with respect to $\mathrm{Cr}$ and Fe. Figure 6e, f are the EDS results for the area of the fusion zone immediately next to HAZ. Once again it is observed that subgrain boundary is enriched in Mo and impoverished in $\mathrm{Ni}$ and $\mathrm{W}$ compared to subgrain body. In addition, it is noticed that there is a significant impoverishment of $\mathrm{Fe}$ at the subgrain boundary. No microsegregation is noticed in respect of $\mathrm{Cr}$.
The EDS results for the PCGTA weldments are shown in Fig. 7. Figures $7 b, c$ are the results for the center part of the fusion zone. Figure $7 \mathrm{~b}$ focuses on the subgrain boundary, while Fig. 7c covers the subgrain body. In contrast to t GTAW, there is no significant difference between the subgrain boundary and subgrain body with reference to levels of any of the elements. The microsegregation that was noticed in GTA fusion zone is essentially 
Table 3 Distribution coefficient $(k)$ of different alloying elements in GTA and PCGTA welded alloy C-276 using ErNiCrMo-4 filler

\begin{tabular}{llllll}
\hline Welding method & $\mathrm{Ni}$ & $\mathrm{Cr}$ & $\mathrm{Mo}$ & $\mathrm{W}$ & $\mathrm{Fe}$ \\
\hline GTA & 1.01 & 1.01 & 0.92 & 1.22 & 0.91 \\
PCGTA & 1.02 & 1.00 & 0.94 & 1.19 & 0.94 \\
Arc welding (Dupont) $^{\text {(Dr }}$ & 1.08 & 0.95 & 0.82 & 1.01 & 1.01 \\
\hline
\end{tabular}

absent in the PCGTA fusion zone. Figures $7 \mathrm{e}, \mathrm{f}$ are the EDS results for the area of fusion zone immediately next to base metal. It is noticed that difference in contents of various elements between the subgrain boundary and subgrain body are much smaller compared to GTA case.

The concept of distribution coefficient $(k)$ was used to quantify the tendency to microsegregation of different elements during cooling of the fusion zone. Perricone and DuPont [11] calculated $\mathrm{k}$ values for various alloying elements in different alloys based on the $\mathrm{Ni}-\mathrm{Cr}-\mathrm{Mo}$ system using the equation:

$k=\frac{C_{\text {core }}}{C_{0}}$,

where $C_{\text {core }}$ is the elemental level in the dendrite core, i.e., point where the first solid forms. $C_{0}$ is the elemental level in the liquid when the first solid forms.

$C_{\text {core }}$ in the present case is the elemental level measured in the subgrain body and $C_{0}$ is the elemental level in the nominal composition of the alloy. Partition coefficients for different elements, calculated by Eq. (1) are displayed in Table 3. Included are the values for both GTAW and PCGTAW. It is noticed that $k$ moves closer to one for both Mo and W on switching over from GTAW to PCGTAW, indicating a reduced microsegregation associated with the latter. As brought out in the Introduction section, similar reduction in segregation in weld fusion zone was caused by pulsing in superalloy 718 [16] and alloy C-276 [15].

The high segregation tendency of the alloying elements Mo and W can be understood in terms of a large difference in atomic radius of matrix element $\mathrm{Ni}$ and atomic radii of Mo and W. The difference is as high as $9 \%$ for Mo and $10 \%$ for $\mathrm{W} . \mathrm{Fe}$ and $\mathrm{Cr}$, in contrast, have atomic radii similar to that of $\mathrm{Ni}$; differences are less than $1 \%$. These elements are not expected to have strong tendency of segregation; observed difference in level of $\mathrm{Fe}$ is believed to be consequence to the segregation tendency exhibited by Mo and W.

The observed microsegregation with respect to Mo, manifesting as enrichment of Mo in the subgrain boundary regions, is expected to lead to the appearance of secondary phases in the microstructure. As pointed out before, TCP phases $\mu$ and $\mathrm{P}$ have been reported in fusion zone microstructures of alloy C-276 and both of them have higher Mo content and lower Ni content compared to the matrix [9] Taking that subgrain boundary regions are richer in $\mathrm{Mo}$ and poorer in $\mathrm{Ni}$, it is possible that some amount of TCP phases $\mu$ and $\mathrm{P}$ appear in these regions. As brought out by Cieslak et al. [10], these phases act as a source for hot cracking during welding. It is also noticed that subgrain boundaries in weld interface regions are enriched to a greater extent with Mo and impoverished to a greater extent with respect to Ni compared to subgrain boundaries in center of the fusion zone. This suggests that $\mathrm{P}$ and $\mu$ phases have a larger presence in weld interface region compared to weld center. The weld interface regions thus constitute a more potential site for hot cracking in alloy C-276 weldments.

The work done in the present research has not provided direct evidence for the presence of $\mathrm{P}$ and $\mu$ phases in the GTA fusion zone. As reported by Cieslak et al. [10], the size of the particles of these phases is of the order of $0.5 \mu$. The EDAX analysis done as part of the present study does not have enough resolution to identify particles with such small size. It may be recalled that Cieslak et al. used TEM study to reveal the presence of $\mathrm{P}$ and $\mu$ phases.

The present study has shown that in contrast to the microsegregation occurring in GTA weldments, PCGTA welding has resulted in essential freedom from microsegregation. This suggests that the occurrence of $\mathrm{P}$ and $\mu$ phases is largely suppressed when PCGTAW is adopted. An important benefit expected to, thereby, accrue is reduction in hot cracking susceptibility of alloy C-276.

\subsection{Mechanical Behavior of Weld Joints}

Strength and ductility of weld joints fabricated by GTAW and PCGTAW were evaluated by carrying out tensile testing of flat specimens cut transverse to the weld joint. Tensile testing of base metal was also carried out for the purpose of comparison. Fracture in case of welded specimens always occurred in the weld joint. The photographs of broken tensile test specimens are shown in Fig. 8a, b. Tensile testing of welded coupons was done in triplicate to ascertain reproducibility of test results. Average strength and ductility values which are the mean of that of three specimens are presented in Table 4 for both GTAW and PCGTAW. It is noticed that PCGTAW joints show not only a higher strength but also a higher ductility. The refinement of fusion zone structure and reduction in severity of microsegregation occurring on switching over from GTAW to PCGTAW are believed to be largely responsible for the all round superiority of mechanical properties of the latter type of joints. The fusion zone in PCGTAW joints, as brought out in "EDS Analysis of GTA and PCGTA Weldments" Section, is expected to be largely free from TCP phases $\mathrm{P}$ and $\mu$. As pointed out in the Introduction section, these phases adversely affect several mechanical properties including tensile ductility. it is thus believed that the small but finite improvement in tensile ductility in PCGTAW joints is due to the relative freedom of the fusion zone from deleterious TCP phases. The freedom from HAZ in case of PCGTAW joints may contribute to their improved mechanical behavior. 

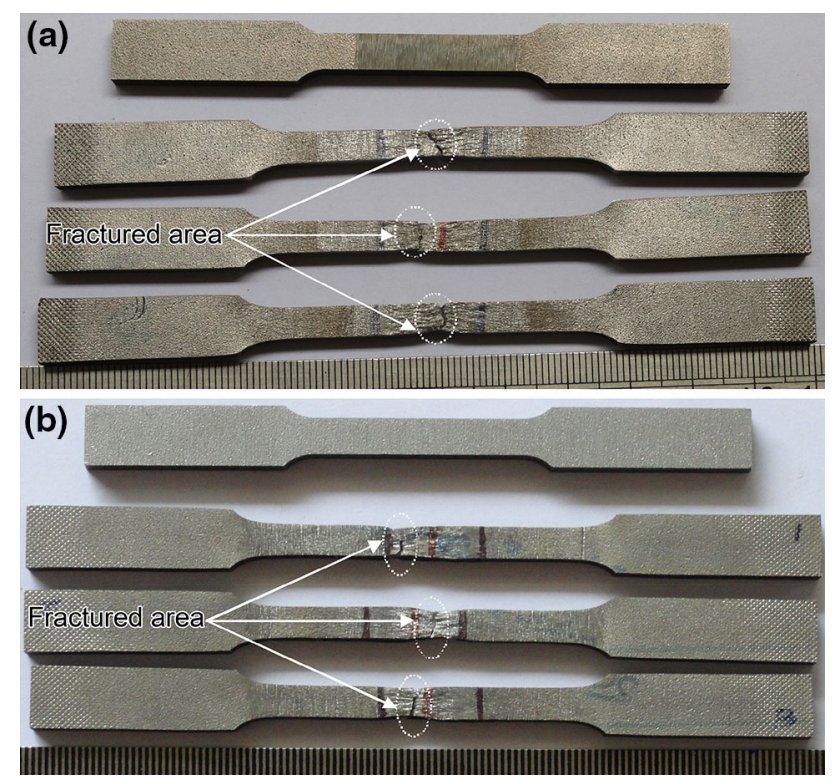

Fig. 8 Photographs of broken tensile test specimens: a GTAWERNiCrMo-4; b PCGTA ERNiCrMo-4

Table 4 Tensile properties of base metal and ERNiCrMo-4 weldments of alloy C-276 using GTAW and PCGTAW

\begin{tabular}{lll}
\hline Material & UTS $(\mathrm{MPa})$ & Elongation $(\%)$ \\
\hline Base metal & 750 & 75 \\
GTA weldment & 766 & 34 \\
PCGTAW weldment & 815 & 41 \\
\hline
\end{tabular}

The UTS and elongation of weldments are the mean value of that of three specimens

The results, in this context, are in agreement with the improvement in impact toughness of joints in superalloy 617 after switching over from GTAW to PCGTAW reported by Farahani et al. [14].

\section{Conclusions}

(1) Narrower welds with smaller HAZ and finer grain structure were produced in alloy C-276 using pulsed current GTAW as compared to continuous current GTAW.

(2) The lower heat inputs coupled with higher instantaneous cooling rates associated with PCGTAW are considered to be responsible for the microstructure refinement in fusion zone arising from pulsing. PCGTAW also causes breakage of dendrite arms contributing to the refinement.

(3) PCGTAW results in reduced microsegregation compared to GTAW. It is believed that the occurrence of secondary constituents $\mathrm{P}$ and $\mu$, deleterious in the context of hot cracking susceptibility of the alloy, also comes down to some extent.
(4) Microsegregation of $\mathrm{Mo}, \mathrm{Ni}, \mathrm{Fe}$, and $\mathrm{Cr}$ is in predicted lines. Observed microsegregation of $\mathrm{W}$ is not in expected line.

(5) PCGTAW gave rise to superior mechanical properties-higher strength and at the same time better ductility, compared to GTAW. The refined grain structure with reduced microsegregation in PCGTAW is believed to be responsible for the improved mechanical properties of the weld joint.

Acknowledgments This research work was supported by the Defence Research Development organization (DRDO) (No. ERIP/ ER/1103952/M/01/1403). We also thank to Department of Science and Technology for the funding received from them under the FIST programme; Instron make universal testing machine used in the present study was procured under this program.

\section{References}

[1] M.J. Cieslak, G.A. Knorovsky, T.J. Headley, A.D. Romig, Metall. Trans. A 17, 2107 (1986)

[2] S.D. Cramer, B.S. Covino Jr, Corrosion: Materials, ASM Handbook, vol. 13B (ASM International, Materials Park, 2005)

[3] M. Manikandan, N. Arivazhagan, M.N. Rao, G.M. Reddy, J. Manuf. Process. 16, 563 (2014)

[4] M. Ahmad, J.I. Akhter, M. Akhtar, M. Iqbal, E. Ahmed, M.A. Choudhr, J. Alloys Compd. 390, 88 (2005)

[5] J.I. Akhter, M.A. Shaikh, M. Ahmad, M. Iqbal, K.A. Shoaib, W.J. Ahmad, J. Mater. Sci. Lett. 20, 333 (2001)

[6] Haynes International, Inc., Haynes International CorrosionResistant Alloys, http://www.haynesintl.com/pdf/h2010.pdf. Accessed 23 October 2013

[7] H.M. Tawancy, J. Mater. Sci. 16, 2883 (1981)

[8] M. Raghavan, B.J. Berkowitz, J.C. Scanlon, Metall. Trans. A 13, 979 (1982)

[9] C.T. Sims, W.C. Hagel (eds.), The Superalloys (John Wiley \& Sons, New York, 1972)

[10] M.J. Cieslak, T.J. Headley, A.D. Romig, Metall. Trans. A 17, 2035 (1986)

[11] M.J. Perricone, J.N. DuPont, Metall. Mater. Trans. A 37, 1267 (2006)

[12] K. Zhao, Y.H. Ma, L.H. Lou, Z.Q. Hu, Mater. Trans. JIM 46, 54 (2005)

[13] C.H. Radhakrishna, K. Prasad Rao, S. Srinivas, J. Mater. Sci. Lett. 14, 1810 (1995)

[14] E. Farahani, M. Shamanian, F. Ashrafizadeh, AMAE Int. J. Manuf. Mater. Sci. 2, 1 (2012)

[15] G.Y. Ma, D.J. Wu, D.M. Guo, Metall. Mater. Trans. A 42, 3853 (2011)

[16] G.D. Janaki Ram, A. Venugopal Reddy, K. Prasad Rao, G.M. Reddy, J.K. Sarin Sundar, J. Mater. Process. Technol. 167, 73 (2005)

[17] G.D. Janakiram, Ph.D Thesis, IIT Madras, 2004

[18] S.G.K. Manikandan, D. Sivakumar, K. Prasad Rao, M. Kamaraj, J. Mater. Process. Technol. 214, 358 (2014)

[19] N. John Dupoint, C. John Lippold, D. Samuel Kiser, Welding Metallurgy and Weldability of Nickel-Base Alloys (A John Wiley \& Sons Publication, Hoboken, 1999)

[20] S.A. David, J.M. Vitek, in International Trends in Welding Science and Technology, Proceedings of 3rd International Conference, ed. by S.A. David, J.M. Vitek (ASM International, Materials Park, Ohio, 1992) p. 147 